\title{
Genomic imprinting and reproduction
}

\author{
A K E Swales and N Spears \\ School of Biomedical and Clinical Laboratory Sciences, University of Edinburgh, Hugh Robson Building, \\ George Square, Edinburgh EH8 9XD, UK \\ Correspondence should be addressed to N Spears; Email: Norah.Spears@ed.ac.uk
}

\begin{abstract}
Genomic imprinting is the parent-of-origin specific gene expression which is a vital mechanism through both development and adult life. One of the key elements of the imprinting mechanism is DNA methylation, controlled by DNA methyltransferase enzymes. Germ cells undergo reprogramming to ensure that sex-specific genomic imprinting is initiated, thus allowing normal embryo development to progress after fertilisation. In some cases, errors in genomic imprinting are embryo lethal while in others they lead to developmental disorders and disease. Recent studies have suggested a link between the use of assisted reproductive techniques and an increase in normally rare imprinting disorders. A greater understanding of the mechanisms of genomic imprinting and the factors that influence them are important in assessing the safety of these techniques. Reproduction (2005) 130 389-399
\end{abstract}

\section{What is genomic imprinting?}

Genomic imprinting is the parent-of-origin specific gene expression and is determined by epigenetic modification of genes, such that gene transcription is altered while the actual gene sequence remains unchanged. Genomic imprinting results in only one inherited copy of the relevant imprinted gene being expressed in an embryo. For paternally imprinted genes, the paternal allele is epigenetically modified to prevent transcription, ensuring that the embryo has only mono-allelic expression from the maternally inherited copy. The opposite is true of maternally imprinted genes, when only the copy inherited from the father is expressed. The fact that particular genes are differentially expressed, according to their parent-of-origin, means that during development the parental genomes are functionally non-equivalent (Surani 1998). Genomic imprinting is vital for normal gene expression patterns in an individual, with errors sometimes resulting in inappropriate gene transcription or repression. Within the mouse genome, approximately 80 imprinted genes have so far been identified (Beechey et al. 2005). It is likely that there will be a similar number of imprinted genes in humans, although fewer have been found to date. Except where stated, this review refers to work on the mouse, as this species has been by far the most extensively studied species.

Within the mammalian genome, the majority of cytosine residues found as CpG dinucleotides (i.e. those cytosines positioned next to a guanine residue) have a methyl group added to their carbon 5 position (Costello \& Plass 2001). It is this addition of the methyl group, referred to as
DNA methylation, that is proposed as the key mechanism (certainly the best studied mechanism) regulating imprinting. It is important to point out, however, that the majority of methylated DNA in the genome is not concerned with genomic imprinting. Heavy methylation of DNA results in a more condensed structure which is resistant to transcription. Thus, if an animal inherits a methylated copy of a gene from its mother and a non-methylated copy from its father, the maternal copy will have its transcription repressed leaving the paternal copy as the only active gene. DNA methylation is an epigenetic modification which can be inherited in a stable manner but is also reversible, allowing gender specific patterns to be initiated in germ cells.

\section{Why did genomic imprinting evolve?}

The most commonly proposed theory explaining the development of genomic imprinting is the genetic conflict or parental investment theory (Moore \& Haig 1991). This theory arose from the observation that many imprinted genes are implicated in the growth and development of the mammalian fetus or placenta. In addition to this, imprinted genes have been shown to exhibit directionality in their actions; that is the majority of the paternally expressed genes, such as Igf2 and Peg3, promote fetal growth and nutrient uptake while in contrast the maternally expressed genes, such as $\lg f 2 R$ and Gnas, tend to curb fetal growth (Reik \& Dean 2001, Tycko \& Morison 2002). Females who could restrict fetal growth and 
produce more offspring from their limited resources would, in the long term, be more successful. In contrast, males would derive long-term benefit from their progeny being larger and stronger even if they achieved this to the detriment of the mother by utilising more maternal nutrients.

An alternative theory to account for the presence of imprinted genes within the genome is the evolvability model (Beaudet \& Jiang 2002). This predicts that species which have genomic imprinting are more able to evolve in response to environmental pressures, as they can induce rapid changes by altering which of the two alleles is silenced and which is expressed. An individual organism can carry an allele which promotes growth that, while imprinted, has no phenotypic effects. Thus, if increased growth becomes advantageous, the relevant allele is already present in the gene pool: by rapid reversal of the imprinting, the allele can be expressed. There is also the 'ovarian time bomb' concept which proposes that genomic imprinting evolved to protect the female from ovarian disease: Varmuza \& Mann (1994) hypothesised that imprinting could limit the level of growth and development of any parthenogenetic embryos within the ovary, thereby preventing malignant trophoblast formation.

\section{How are DNA methylation patterns regulated?}

DNA methyltransferases (Dnmts) carry out methylation of DNA; these can be broadly divided into Dnmt1, Dnmt2 and Dnmt3 families. The three families of Dnmts are related, albeit distantly, and are believed to have diverged from their common ancestors prior to the separation of the animal and plant kingdoms (Howell et al. 2001). Members of both the Dnmt1 and Dnmt3 families have been identified as having active transmethylase activity and their functions have been partially elucidated, with the Dnmt3 family being primarily concerned with laying down new methylation patterns while the Dnmt1 family appears to be mainly involved in the maintenance of these patterns during cell division. Initial studies on Dnmt2 did not find any active methylation function for this protein but more recent research has challenged this concept, with work by several groups finding that this enzyme can act as a methyltransferase which targets a very specific DNA sequence, explaining the low level of identifiable activity (Liu et al. 2003, Hermann et al. 2003, Tang et al. 2003). Although capable of binding to methylated DNA, the definitive binding specificity of Dnmt2 has yet to be determined (Hermann et al. 2003). Golding \& Westhusin (2003) have shown that Dnmt2 is actually the most prevalent Dnmt in the bovine adult ovary and testis.

\section{Laying down of methylation patterns}

To allow reprogramming of the germ cell, the genome must undergo demethylation (as described later). Once the initial imprints have been removed the appropriate new pattern must be established, thus ensuring that the paternal- and maternal-specific imprints are laid down in the sperm and oocyte respectively. The enzymes which are capable of laying down the new methyl groups onto previously unmethylated DNA are from the Dnmt3 family. Members of this family which have active transmethylase activity are Dnmt3a and Dnmt3b, which share a high degree of sequence homology but have been shown to have different expression patterns and timing through development. The third member of this family, Dnmt3l, shares sequence homology with the other enzymes but is missing the catalytic domain needed to add methyl groups onto DNA. After both examining the localisation of this protein and using mice with a disrupted Dnmt3/ gene, a role in the establishment of maternal imprints in the oocyte has been hypothesised for this enzyme, as discussed below.

\section{Maintenance of methylation}

When a methyl group is added onto already hemimethylated DNA during cell replication (necessary if the daughter cells are to maintain the methylation pattern of the cell undergoing mitosis), the process is termed maintenance methylation. Dnmt1 has the primary responsibility for maintaining the methylation status of DNA. The most common form of this methyltransferase is that found in all somatic cells, Dnmt1s, and has been shown to be vital for development. In addition, there are two splice variants identified which are specific to the germ cells and early embryo. Dnmt1p is found in pachytene spermatocytes whilst Dnmt1o is only identifiable in the oocyte and pre-implantation embryo. It is not until embryonic day 7 (E7) that the embryo is capable of producing full-length Dnmt1s protein.

Interestingly, although Dnmt1 has been identified as the main maintenance methylase in vivo, studies in vitro have shown that this enzyme has a higher de novo methylase activity than either Dnmt3a or Dnmt3b. In vivo, Dnmt1 de novo methylase activity has yet to be found, but the possible implications of this in vitro activity should be borne in mind (Howell et al. 2001).

\section{How does methylation lead to repressed gene transcription?}

There are two main mechanisms by which the methylation of DNA can prevent the transcription of genes. The first of these is by the methyl group causing direct interference preventing particular transcription factors from binding to methylated DNA (Iguchi-Ariga \& Schaffner 1989). The second mechanism results from methyl-binding domain proteins (MBDs) binding to methylated DNA.

Of the MBDs identified to date, MBD1 to MBD3 and methyl CpG-binding protein 2 (MeCP2) are involved in transcriptional repression (Nan et al. 1997, Fujita et al. 1999, Ng et al. 1999), while MBD4 is thought to have a role as a mismatch repair protein (Hendrich et al. 1999). 
MBD1 and MeCP2 both contain transcriptional repression domains which act via histone deacetylases (HDACs). HDACs cause local deacetylation of the histone tails which, in turn, results in remodelling of the chromatin into a more condensed structure that is resistant to transcription (Taunton et al. 1996). MBD1 mediates transcriptional repression through recruitment of a histone methylase capable of binding HDACs ( $\mathrm{Ng}$ et al. 2000, Fujita et al. 2003), while MeCP2 acts to bind a co-repressor complex containing an HDAC (Jones et al. 1998, Nan et al. 1998), although MeCP2 has also been shown to cause transcription repression in the absence of HDAC activity (Nan et al. 1998, Yu et al. 2000). MBD2 and MBD3 are both components of a large protein complex, MeCP1 (Feng \& Zhang 2001). MeCP1 binds methylated DNA in a non-sequence-specific manner. The binding of MeCP1 to methylated DNA is due to the presence of MBD2 in the complex ( $\mathrm{Ng}$ et al. 1999). Interestingly, the mammalian form of MBD3 appears not to bind directly to methylated DNA (Hendrich \& Bird 1998). The MeCP1 complex binds methylated DNA less tightly than MeCP2, which suggests that long-term transcriptional repression may be maintained by the permanent binding of MeCP2, with more transient transcriptional silencing determined by the binding of the MeCP1 complex (Ng et al. 1999). In addition to the MBD family, there is a further binding protein termed Kaiso which is capable of methylation-dependent repression of gene transcription. Although it is not an MBD-containing protein, it is capable of binding to methylated DNA via its zinc finger (Prokhortchouk et al. 2001). Kaiso has been shown to be a vital component of amphibian development; blocking translation of this protein is lethal (Ruzof et al. 2004) but the extent of its role in mammalian systems has yet to be established. Methylationdependent transcriptional repression is covered by many good reviews such as Wade (2001) and Li (2002).

Transgenic studies show that mice lacking MBD1 have no observable phenotype, although problems within the nervous system are evident at the molecular level (Zhao et al. 2003). Mbd2 knockout (KO) mice are also viable, although they exhibit impaired maternal behaviour (Hendrich et al. 2001). Mbd3 null mutations are embryo lethal (Hendrich et al. 2001). The abnormal phenotype of Mecp2 $\mathrm{KO}$ mice develops from several weeks of age and is lethal by 8 weeks of age, with all known abnormalities having their origin in the nervous system (Guy et al. 2001). The fact that Mbd1, Mbd2 and Mbd3 KO mice have no apparent phenotype outside of the nervous system suggests that there is a degree of redundancy within the MBD-mediated system of transcription control. Although a double $\mathrm{KO}$ of Mbd2 and Mecp2 has demonstrated that both these proteins function in separate pathways, this does not rule out co-operation between other members of the MBD family (Guy et al. 2001).

\section{Genomic imprinting in germ cells and embryos Primordial germ cells}

When primordial germ cells (PGCs) are first seen in the mouse embryo at E7 they, and the surrounding somatic cells, carry the maternally and paternally inherited imprinting patterns. This DNA methylation pattern is maintained in PGCs as they migrate to the developing gonad. Coincident with their arrival in the gonadal ridge, the mouse PGCs begin to undergo global demethylation from around E11.5 to remove their inherited imprinting pattern. During this period, DNA methylation of the somatic cells is maintained (Fig. 1). Demethylation of germ cells is clearly vital if the correct sex-specific epigenetic information is to be subsequently laid down during oocyte and sperm maturation. Demethylation is complete by E13-14, correlating to the period when the male and female mouse PGCs begin to enter mitotic and meiotic arrest respectively. It has been suggested that mitotic/meiotic arrest might necessarily follow demethylation because replication of unmethylated DNA has an increased risk of unrepressed retro-transposons moving and causing mutations (Walsh et al. 1998). The time at which this demethylation occurs, and also the amount of methylation lost, appears to be identical regardless of the gender of the embryo (Hajkova et al. 2002). Whether the loss of methylation occurs by a passive or active mechanism or a combination of both is not yet known, although the speed with which this occurs would suggest involvement of an active mechanism.

\section{Oocyte development}

In female embryos, the gonad forms as an ovary with germ cells forming primordial follicles. As long as the primordial follicle and the oocyte contained within it are not activated to enter the growing population, the methylation level of the oocyte genome remains low and unchanged. It is during the growth phase of the oocyte that the maternal imprints are laid down on the genome (Fig. 1). The imprints are not all established at the same time; instead, each imprinted gene has a specific time at which it will become methylated (Fig. 2). Obata \& Kono (2002) analysed parthenogenetic embryos created by nuclear transfer of oocyte nuclei from different stages of follicle development, with the aim of establishing the timing of the maternal imprinting within the oocytes, and showed that Snrpn, Znf127 and Ndn genes are imprinted early in follicle development during the primordial to primary follicle stages, whilst imprinting of Peg3, Igf2r and $p 57^{K I P 2}$ happens at the secondary follicle stage. There are also genes which become imprinted at even later stages of follicle development, including Peg1/mest during tertiary to early antral stages and Impact which only becomes imprinted in the oocyte within an antral follicle (Obata \& Kono 2002). A further study by Lucifero et al. (2004) 


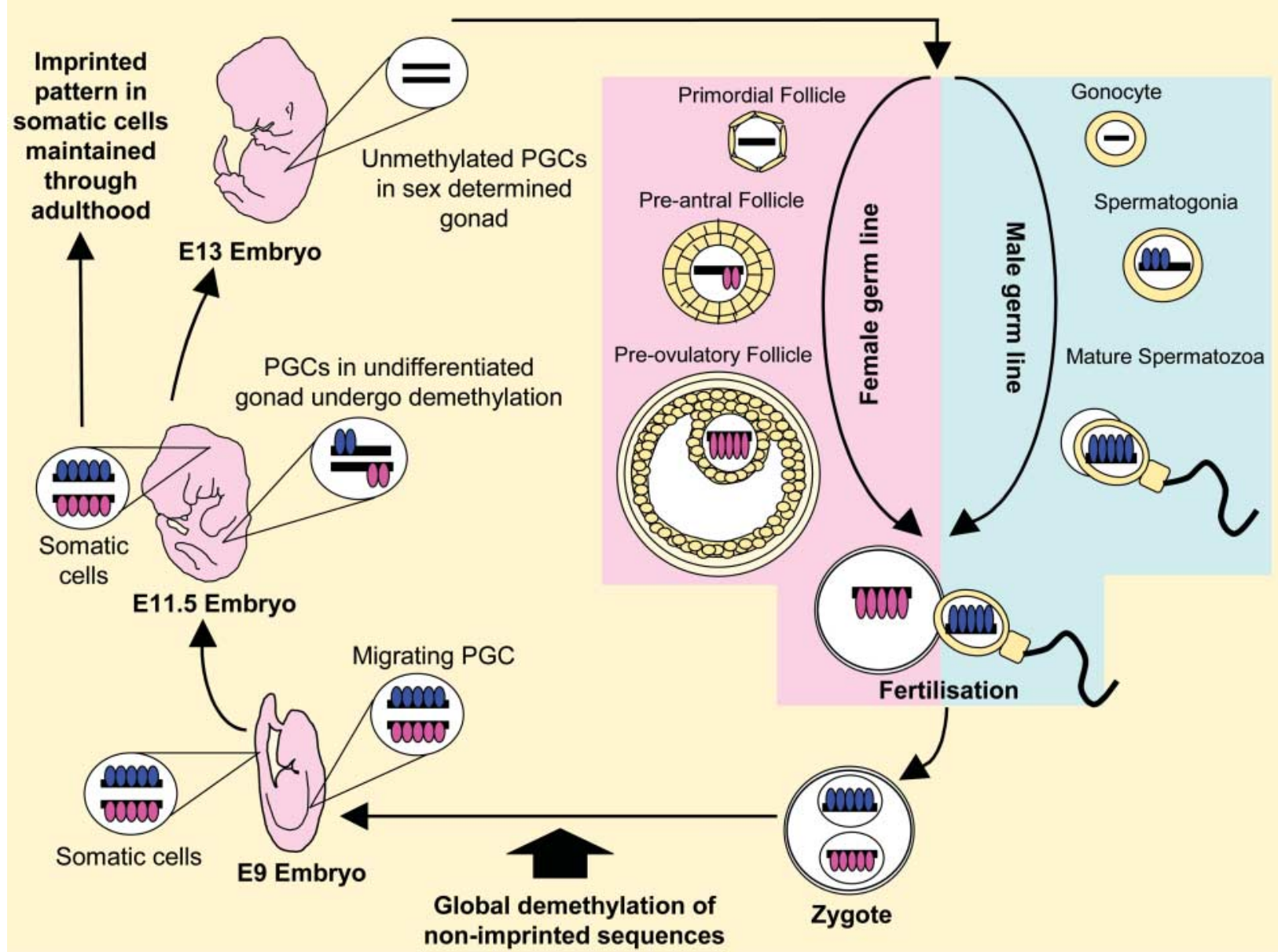

Figure 1 The maternal (pink shaded region) and paternal (blue shaded region) imprints are laid down during germ cell development so that by the time the oocyte and sperm are fully mature the correct pattern of DNA methylation is present on the genome (female imprints, pink ovals; male imprints, blue ovals). After fertilisation (yellow-shaded area), both parental genomes undergo global demethylation of non-imprinted sequences: imprinted genes are protected from this process. During early embryo development the imprinted genes of both the somatic and PGC retain the parental imprints. From E11.5 the primordial germ cells begin to undergo demethylation to erase the inherited parental imprints, but the somatic cells of the embryo maintain the parental imprints through embryo development and into adulthood. The process of PGC demethylation is complete by E13. Subsequent reprogramming of the germ cells occurs when the gender-specific imprinting patterns are once more laid down.

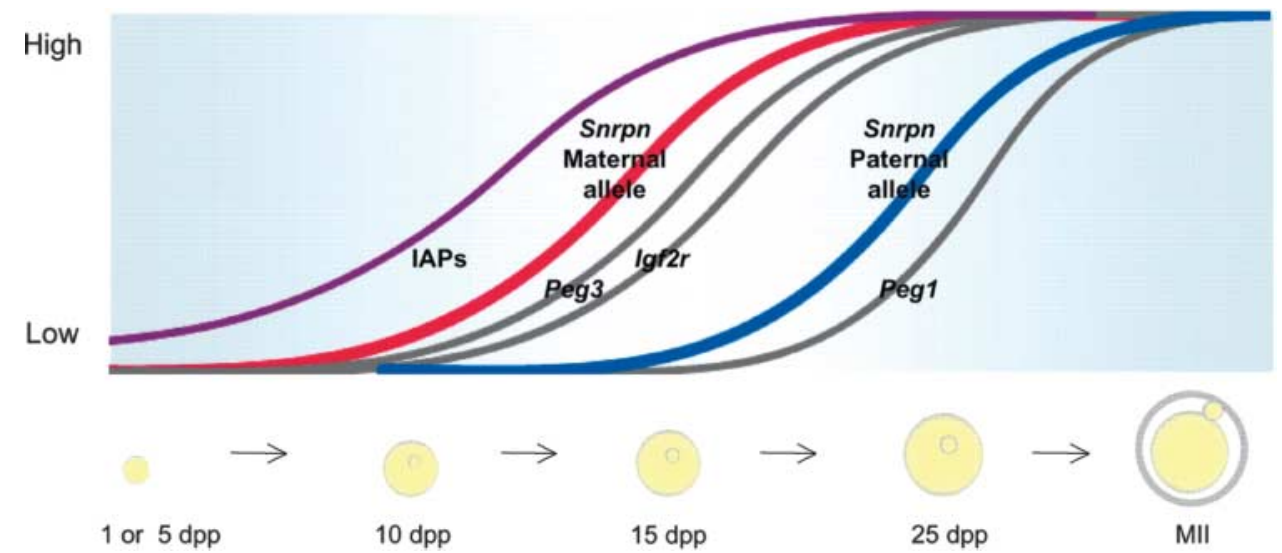

Figure 2 Methylation levels of individual imprinted genes and non-imprinted regions of the genome were assessed over the period of oocyte growth and development. These results demonstrate the gene-specific nature of methylation of the genome, with some genes imprinted early on in follicle development while others are imprinted much later. dpp, days post partum; MII, Metaphase II; IAP, intracisternal A particles; Reproduced from Lucifero et al. (2004) with permission from Oxford University Press. 
investigated the methylation of imprinted genes by dissecting follicles from ovaries of different postnatal ages and examining the oocytes. This confirmed the earlier Obata \& Kono, 2002 study in that Peg3, Igf2r and Snrpn began to gain methylation earlier in development than Peg1. By the early antral stages, some differentially methylated regions (DMRs) were fully methylated in all genes other than Peg1, while it was not until oocytes were fully mature that Peg1 appeared to undergo rapid de novo methylation. Thus, the imprinting pattern of the oocyte is not fully laid down until it is within a mature follicle ready to ovulate. This has clear implications for assisted reproductive techniques (ARTs), where follicle and oocyte maturation is usually artificially stimulated; any such process must support the correct completion of oocyte imprinting.

Over the period of oocyte growth, the general level of DNA methylation increases as both the appropriate maternal pattern of imprinting is laid down and nonimprinted sequences also become methylated (Fig. 3). The Dnmt involved has yet to be identified, although it has been suggested that one or more members of the Dnmt3 family could be responsible. Dnmt3a, $3 \mathrm{~b}$ and $3 \mathrm{l}$ are all expressed during postnatal oocyte growth. Dnmt3l is expressed at a higher level than either Dnmt3a or Dnmt3b, although all three have maximal expression levels occurring at approximately the same stage of oocyte development (Lucifero et al. 2004). Dnmt1s protein is not found in either growing oocytes or in pre-implantation embryos. Instead, an alternatively spliced, more stable transcript, Dnmt1o, is expressed at these stages. In the growing oocyte, Dnmt1o is found in both the cytoplasm and the germinal vesicle (Fig. 4), but once the oocyte is fully matured, it is localised to the cytoplasm where it is stored until it is required during later embryo development (Carlson et al. 1992, Mertineit et al. 1998). Since Dnmt1o translation only occurs early in oocyte development, the stability of this form of Dnmt 1 is clearly important.

Dnmt3I does not have the active transmethylase activity which is a characteristic of the other Dnmt3 family proteins, Dnmt3a and 3b. However, Hata et al. (2002) found that Dnmt3l expression was vital if normal maternal imprints were to be laid down in the oocyte and that this function may be mediated through its ability to bind and co-localise with both Dnmt3a and 3b. Mice with a disrupted Dnmt3/ gene are sterile. Males produce no mature sperm (see below); females undergo apparently normal oocyte growth and the resulting oocytes can be fertilised, but the absence of maternal Dnmt3/ is embryo lethal to heterozygote offspring by E9.5 (Bourc'his et al. 2001). Interestingly, a conditional KO with disrupted Dnmt3a in the germ cells has an almost identical phenotype to the Dnmt31 ${ }^{-1-}$ mouse (Kaneda et al. 2004): when females whose oocytes lacked Dnmt3a were crossed with wildtype males all offspring died by E11.5, with embryos lacking methylation on the normally methylated maternally imprinted genes (resulting in inappropriate gene expression). This study demonstrates the essential role of Dnmt3a in the establishment of maternal imprints. Kaneda et al. (2004) also investigated the role of Dnmt3b using a conditional $\mathrm{KO}$; these animals were found to be phenotypically normal and were able to produce viable offspring.

\section{Sperm development}

As with the oocyte, new imprints are laid down as sperm develop (Fig. 1), with the increase in DNA methylation levels not just attributable to the establishment of paternal imprints but also the methylation of other non-imprinted sequences, such as intracisternal A particles (IAPs) becoming methylated (Walsh et al. 1998). The paternally expressed (i.e. maternally imprinted) human MEST/PEG1 gene is demethylated during fetal life and then remains unmethylated through all stages of sperm development in adult life. Ueda et al. (2000) analysed the methylation level of an imprinted gene, H19, in male germ cells and found that the H19 imprint is laid down early in germ cell development before meiosis occurs. The same result was found in humans, with the $\mathrm{H} 19$ gene becoming methylated before meiosis at the spermatogonial stage of development (Kerjean et al. 2000). In general, though, there is less information about the laying down of imprinting patterns during sperm development compared with what is known about imprinting in oocytes.

The resumption of mitotic division of male germ cells at puberty coincides with an increase in the level of Dnmt1 within the spermatocytes. During the early stages of
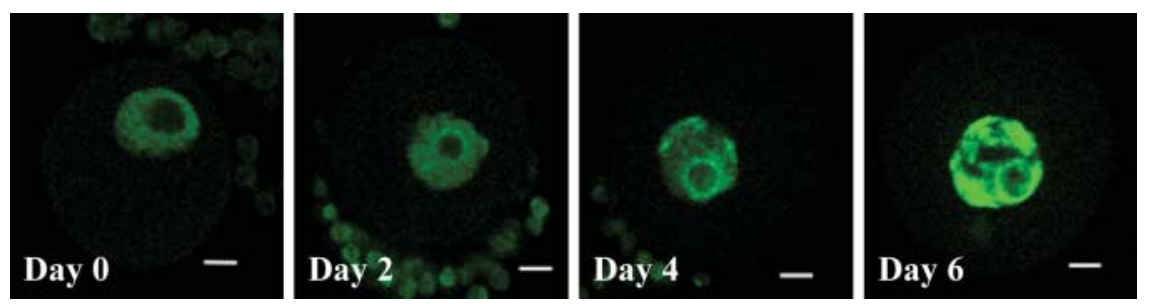

Figure 3 Global methylation level of the oocyte increases over the period of growth and development associated with follicle development from pre-antral stages to full maturity. Confocal images showing oocytes stained with 5-methyl-cytosine antibody (Eurogentec, Seraing, Belgium) and an FITC fluorescent secondary antibody (Jackson ImmunoResearch, West Grove, PA, USA). Late pre-antral follicles were dissected from 3-weekold mouse ovaries and cultured as in Spears et al. (1994), with follicles developing to the Graafian stage over a 6-day period. Follicles were removed from culture and oocytes recovered on days $0,2,4$ and 6 of culture before being fixed and stained. White scale bars represent $10 \mu \mathrm{m}$. 

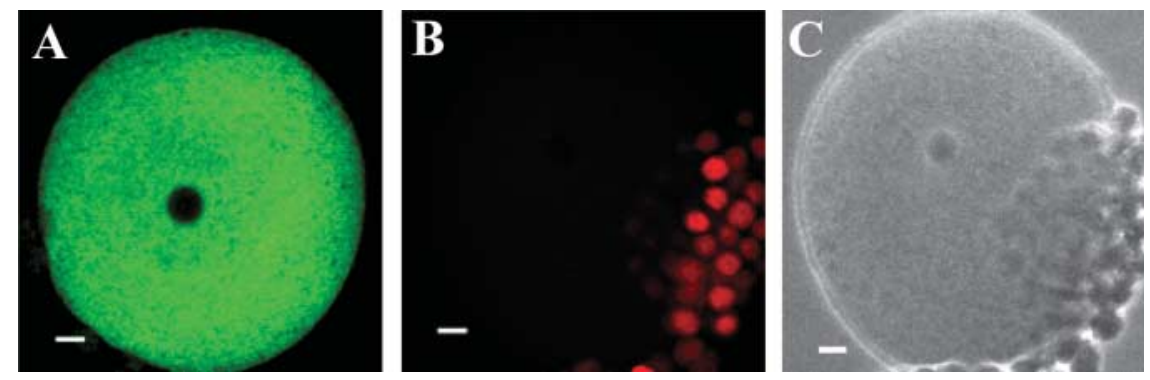

Figure 4 The oocyte expresses only Dnmt1o (and not Dnmt1s). Until oocyte maturation is complete, Dnmt1o is localised in the cytoplasm and germinal vesicle - but not the nucleolus - of growing oocytes. The figure shows an oocyte from a mid-antral (i.e. not yet fully mature) follicle. (A) Immunocytochemistry using the PATH52 antibody that recognises both Dnmt1s and Dnmt1o (kindly donated by T Bestor, Columbia University). The image shows localisation of Dnmt1 in both the cytoplasm and the germinal vesicle of the oocyte, with only the nucleolus remaining unstained. (B) Immunocytochemistry using the UPT82 antibody which detects only Dnmt1s (kindly donated by J R Chaillet, University of Pittsburgh). The cumulus cells are heavily stained while, as expected, the oocyte remains unstained showing that staining in (A) was specifically due to Dnmt1o. (C) Transmitted light image of oocyte shown in (B). White scale bars represent $10 \mu \mathrm{m}$.

meiosis the level of Dnmt1s in spermatocytes is high but a reduction in the level of the Dnmt1 enzyme has been observed in pachytene stage spermatocytes (Jue et al. 1995). This is due to the expression of an alternatively spliced version, Dnmt1p, which does not appear to be translated. Although Dnmt1s within the sperm is normally found in both the nucleus and the cytoplasm, it is concentrated at nuclear foci during some stages of meiosis and it may be that this correlates with the laying down of paternal imprints (Jue et al. 1995). Dnmt3l is expressed in the murine testes from E12.5 in non-dividing prospermatogonia with peak expression seen at the time of birth, after which there is a dramatic postnatal reduction in expression level (Bourc'his \& Bestor 2004, La Salle et al. 2004). Dnmt3a expression in the testis is raised before birth and during early postnatal life, in contrast to the level of Dnmt3b expression which is lower during embryonic life and rises postnatally (La Salle et al. 2004). Mice lacking Dnmt3/ have smaller testes, and by adulthood there are virtually no spermatozoa present, resulting in sterile animals (Hata et al. 2002). Dnmt3/ is required if normal meiosis and silencing of retrotransposons is to occur (Bourc'his \& Bestor 2004). The loss of Dnmt3a results in a similar although less extreme phenotype than that seen in the Dnmt3/ KO mouse (Hata et al. 2002). More recently, the male Dnmt3a conditional KO was created, with no germ cell Dnmt3a expression but with somatic cell levels maintained (Kaneda et al. 2004). Spermatogenesis is severely impaired in these mice so that by 11 weeks of age there are no spermatozoa in the testis, demonstrating a vital role for Dnmt3a in this process. Offspring from these conditional $\mathrm{KO}$ males have errors in the methylation of some paternally imprinted genes.

\section{Fertilisation and early embryo development}

As shown in Fig. 1, the fertilised embryo contains methylated DNA, some of which will be located in imprinted genes (both maternal and paternal) while the majority of the DNA methylation will be positioned on non-imprinted sequences (again of both maternal and paternal origin). Early on in embryo development, the embryo loses its methylation at the non-imprinted DNA sequences; it now appears that this DNA methylation is lost in a parent-oforigin specific order, at least in some species. Imprinted genes are resistant to these early demethylation processes. The embryo's germ cells will lose methylation of the imprinted genes during gonadal development, while somatic cells maintain these methylation patterns throughout embryonic development and, in the main, throughout the life of the newly formed organism (although imprinted patterns are lost or altered in some tissues, such as the liver; McLaren \& Montgomery 1999).

In some species (such as the mouse), the paternal genome is actively demethylated immediately after fertilisation (Oswald et al. 2000). The occurrence and degree of this demethylation appears to be species specific, and its regulation is currently unknown. Cross-fertilisation using gametes from several species of animal has shown that, although there are sperm characteristics which affect the degree of demethylation, the main factor determining whether the paternal genome becomes demethylated is oocyte specific (Beaujean et al. 2004). In the search for the factor responsible for this post-fertilisation active demethylation, MBD2 was proposed as a candidate after an in vitro study by Bhattacharya et al. (1999). However, a subsequent study utilising $M B D 2^{-1-}$ oocytes has found that the rapid demethylation of the paternal genome still occurs in its absence (although this result does not eliminate the possibility of redundancy; Santos et al. 2002). The maternal genome undergoes passive demethylation which is slower to occur and is linked to the replication of DNA in the absence of any maintenance methylase activity. Although the general trend after fertilisation is for nonimprinted sequences to undergo demethylation, there does appear to be some specific incidences of de novo methylation such as the DMRs of the Dnmt1o gene in the one-cell to blastocyst stage embryo (Ko et al. 2005). 
Dnmt1o remains localised to the cytoplasm of the embryonic cells at all pre-implantation stages with the exception of the eight-cell embryo. During this stage, the protein has been shown to translocate to the nuclei, where it is thought to play a role in maintaining the methylation level of imprinted genes. Dnmt3a is expressed by pre-implantation embryos and there is no evidence of the protein being excluded from the nucleus at any developmental stage (Ko et al. 2005). Although Dnmt3b is not transcribed in the pre-implantation embryo the protein is present at all stages from the one-cell to the blastocyst stage; while mainly localised to the cytoplasm, it is not fully excluded from the nucleus (Ko et al. 2005).

Until recently, embryos which consisted of two maternal or two paternal genomes were unable to develop to term. Work examining the competence of parthenogenetic embryos found they were able to develop at best until E9.5. By creating an embryo with one set of chromosomes from a fully grown and the other from a non-growing oocyte, Kono et al. (1996) showed that embryo development could be extended to E13.5. It was thought that this increase in the length of time the embryo survived was due to the ability of the non-growing oocyte chromosomes (with, therefore, no female imprints yet laid down) to partially compensate for the lack of a paternally imprinted set of chromosomes. Parthenotes which died at E9.5 and E13.5 had incorrect biallelic expression of the normally monoallelic $\mathrm{H} 19$ gene. The most recent work by Kono et al. (2004) has resulted in the birth and survival of a viable parthenote. This was achieved using non-growing oocytes from a transgenic mouse with a $13 \mathrm{~kb}$ deletion of $H 19$. The mouse had H19 expression consistent with that normally seen from the paternal genome. As $\mathrm{H} 19$ in turn influences the expression of the imprinted lgf 2 gene, the embryo had monoallelic expression of both $\mathrm{H} 19$ and Igf2 (from the wild-type fully grown oocytes only), as would be the case in normal embryos. The fact that normal embryo development is possible after the female genome is altered to more closely resemble the genomic imprinting pattern of the male genome demonstrates the importance of this mechanism in controlling development, reinforcing the idea that the presence of mammalian genomic imprinting might act as a barrier to parthenogenesis (see above).

\section{Errors in genomic imprinting}

With genomic imprinting being a basic mechanism clearly vital for many aspects of development, there are, not surprisingly, many instances of developmental defects due to imprinting errors whether occurring naturally or during human intervention (Table 1).

\section{Assisted reproductive techniques}

In recent years, there has been increasing concern that children conceived with the aid of ARTs could have an increased occurrence of disorders linked to imprinting problems. At the turn of the century, two studies (Cox et al. 2002, Orstavik et al. 2003) reported the occurrence of three children conceived using intra-cytoplasmic sperm injection (ICSI) with Angelman syndrome (AS), a neurological disorder characterised by developmental delay and seizures, suggesting that the risk of AS may be increased by the use of ICSI. The fear of such a link was then increased with three studies that examined patients with Beckwith-Wiedemann syndrome (BWS) to see if a higher than expected proportion of these cases came from ART babies; all studies found a disproportionate number of such cases (DeBaun et al. 2003, Gicquel et al. 2003, Maher et al. 2003). BWS is characterised by both pre- and postnatal overgrowth and defects of the abdominal wall. Children who had been conceived using ART and suffered from BWS had the methylation status of their H19 and LIT1 genes established, with only one of the identified children demonstrating normal methylation patterns on both these genes. Data suggest that ART results in a threeto sixfold increase in the incidence of the normally rare BWS, although some of the studies may in fact be underestimating the true risk (DeBaun et al. 2003).

The cause of the link between ARTs and imprinting disorders is currently unknown. It could be due to some aspect of the ARTs involved. There is a wide range of different ARTs which are now routinely used within clinics. Techniques might expose one or both of the germ cells to an altered hormonal regime in vivo, a period of time in culture or mechanical manipulation. Any such alterations to the normal environment of the oocyte or sperm could result in changes to some aspect of their imprinting mechanisms. Alternatively, it could be due to some error within the germ cells used, bearing in mind that couples seeking to use ARTs have reduced natural fertility.

The potential problems do not end with the germ cells; the pre-implantation embryo is also often exposed to a period of culture which could again alter the epigenetic reprogramming known to occur at these early stages. One such example is abnormal biallelic H19 expression of mouse embryos cultured in Whitten's media (Doherty et al. 2000). It is not just in humans and mice that potential problems with imprinting have been seen. In large domestic mammals such as sheep and cattle, large offspring syndrome (LOS) was identified when embryos had been exposed to some time in culture (Young et al. 1998). Further investigations into LOS in sheep have identified changes in the expression level of the imprinted gene, IGF2R, due to epigenetic changes (Young et al. 2001). Similar overgrowth problems seen in mice and humans are often caused by errors in several imprinted genes including lgf2 and H19 (Eggenschwiler et al. 1997), suggesting that other genes responsible for fetal growth and development could be involved in LOS.

If sperm used for in vitro fertilisation have lowered global methylation levels there is no alteration in either fertilisation rate or in early embryo quality; however, there is a reduction in pregnancy rate, demonstrating the importance 
Table 1 Diseases and syndromes which result from problems to the imprinting mechanisms or from errors in the imprinting of genes.

\begin{tabular}{|c|c|c|c|}
\hline Disorder & Affected genes & Phenotype & Art link? \\
\hline Angelman syndrome & $\begin{array}{l}\text { Chromosome } 15 \text { - maternal copy, loss } \\
\text { of SNRPN imprinting }\end{array}$ & $\begin{array}{l}\text { Mental retardation, ataxic gait, seizures, sociable } \\
\text { disposition }\end{array}$ & Yes \\
\hline Autism & $\begin{array}{l}\text { Unknown X-linked gene (not always } \\
\text { connected to imprinting) }\end{array}$ & $\begin{array}{l}\text { Impaired language development, problems with } \\
\text { social and motor skills }\end{array}$ & \\
\hline Beckwith-Wiedemann syndrome & $\begin{array}{l}11 \mathrm{p} 15 \text { region - altered expression of } \\
\text { IGF2, H19 and LIT1 }\end{array}$ & $\begin{array}{l}\text { Undescended testes, large newborn, seizures, } \\
\text { abdominal wall defects }\end{array}$ & Yes \\
\hline Cancer & $\begin{array}{l}\text { Variable, e.g. IGF2 in lung cancer } \\
\quad \text { (not always connected to imprinting }\end{array}$ & Tumours & \\
\hline $\begin{array}{l}\text { ICF (immunodeficiency, centromeric } \\
\text { region instability and facial } \\
\text { anomalies syndrome) }\end{array}$ & DNMT3B & $\begin{array}{l}\text { Immune problems, facial anomalies, } \\
\text { growth retardation }\end{array}$ & \\
\hline Paraganglioma & $\begin{array}{l}\text { Paternal mutations SDHA (PGL1) } \\
\quad \text { and PGL2 }\end{array}$ & $\begin{array}{l}\text { Glomus tumours of the parasympathetic } \\
\text { ganglia mainly in the head and neck region, } \\
\text { tend to be slow growing and benign }\end{array}$ & \\
\hline Prader-Willi Syndrome & Chromosome 15 - paternal copy & $\begin{array}{l}\text { Undescended tests, mental retardation, short } \\
\text { stature, obesity small hands and feet }\end{array}$ & \\
\hline Pre-eclampsia & Not yet defined & Serious complication of pregnancy & \\
\hline $\begin{array}{l}\text { Pseudohypoparathyroidism type IA } \\
\text { (Albright hereditary osteodystrophy) }\end{array}$ & Imprinted GNAS cluster & $\begin{array}{l}\text { Parathyroid horomone resistance, short } \\
\text { stature, round face and short hand bones }\end{array}$ & \\
\hline Pseudohypoparathyroidism type IB & Imprinted GNAS cluster & $\begin{array}{l}\text { Parathyroid hormone resistance localized } \\
\text { to renal system, causing hypocalcaemia } \\
\text { and hyperphosphataemia }\end{array}$ & \\
\hline Rett syndrome & $\mathrm{MeCP} 2$ & $\begin{array}{l}\text { Childhood neurodevelopmental disorder mainly } \\
\text { affecting females. Loss of motor function } \\
\text { and mental retardation }\end{array}$ & \\
\hline Silver-Russell syndrome & $\begin{array}{l}\text { Cases which are imprinting } \\
\text { related - chromosome } 7\end{array}$ & $\begin{array}{l}\text { Short stature, excessive sweating, triangular face, } \\
\text { inward curving 5th fingers and coloured spots } \\
\text { on the skin }\end{array}$ & \\
\hline Transient neonatal diabetes & $\begin{array}{l}\text { An imprinted gene at } 6 q 24 . \\
\text { Candidates are } Z A C \& \text { HYMAI }\end{array}$ & $\begin{array}{l}\text { Growth retardation and diabetes which develops } \\
\text { during the first } 6 \text { months of life but corrected } \\
\text { by } 18 \text { months }\end{array}$ & \\
\hline Turner syndrome & $\begin{array}{l}\text { Complete or partial loss of second } \\
\text { X chromosome }\end{array}$ & $\begin{array}{l}\text { Affects females - short stature, social problems } \\
\text { and ovarian failure }\end{array}$ & \\
\hline Wilms' tumour & IGF2 loses imprinting & Childhood kidney tumour & \\
\hline
\end{tabular}

of normal gamete DNA methylation on embryo development and ultimately ART outcome (Benchaib et al. 2005). There is recent evidence that sperm obtained from males with low sperm counts due to abnormal spermatogenesis have incorrect genomic imprinting (Marques et al. 2004), although such sperm can then be used, for example, in ICSI. Marques et al. (2004) found that, although the maternal imprints had been erased from all sperm, the paternally methylated $\mathrm{H} 19$ gene was under-methylated in some sperm from the oligozoospermia donors. Any embryo derived from one of these hypomethylated sperm could have inappropriate expression of the imprinted $\mathrm{H} 19$ and IGF2 genes, the effect of which is not known.

\section{Cloning}

Studies investigating the failure of cloned animals have also turned their attention to the role of genomic imprinting. The fact that many of the errors seen in cloned animals have epigenetic causes has been demonstrated by examining the offspring of cloned mice. These cloned mice were obese but this trait was not passed onto the offspring, demonstrating that this was not a genetic error but due to epigenetics. This finding is important as it suggests that, despite any problem in the cloned animals, it is possible that their germ cells are able to correctly undergo genomic imprint reprogramming (Tamashiro et al. 2002). In bovine cloned embryos, it has been found that the levels of methylation in the cells of the embryo are higher than normal at the four-cell and eight-cell stages. Although there is initial demethylation of the donor genome, passive demethylation does not occur to the level seen in normal embryos. In addition to a reduction in the amount of demethylation, there also appears to be inappropriate de novo methylation occurring at early stages of embryo development (Dean et al. 2001). It is also possible that errors in the Dnmt enzymes normally present in the early embryo could account for alterations in methylation seen in these embryos. Analysis of cloned mouse embryos shows inappropriate presence of Dnmt1s within the preimplantation embryo; this transcript of Dnmt1 is never present in normal embryos. It was also observed that at the eight-cell stage, when Dnmt1o would normally translocate into the nuclei of embryonic cells, some nuclei within each embryo were devoid of any Dnmt1 transcript, suggesting that these cells are unable to maintain normal methylation patterns (Chung et al. 2003). 


\section{Disease}

In some cases, imprinting errors can occur which, although not embryo lethal, cause abnormal physiological processes and lead to disease. Such diseases can arise when any imprinted gene becomes hypermethylated or hypomethylated. Effects are not always limited to the loss of function of a single gene, as some imprinted genes affect the expression of other genes, such as H19 and IGF2. The linked Prader-Willi syndrome (PWS) and AS are examples of disorders that can occur when correct imprinting is lost. A loss of a currently unidentified imprinted gene results in PWS when the deletion is paternally inherited, whereas the same errors cause AS to develop when maternally transmitted (Moncla et al. 1999). Other examples of diseases which result after incorrect imprinting include BWS, Silver-Russell syndrome and transient neonatal diabetes.

Disease can also result from defects in mechanisms regulating imprints. One of the key groups of enzymes with a role in genomic imprinting are the Dnmts which are responsible for the addition of methyl groups to the DNA. When problems arise within this aspect of the imprinting mechanism it can lead to disease in the individual. One such example is immunodeficiency, centromeric region instability and facial anomalies syndrome which is a result of a mutation in DNMT3B (for review see Ehrlich 2003).

Another major component of the imprinting mechanism is the family of methyl-binding domain proteins. MeCP2 is a protein which contains a methyl-binding domain. It has a role in controlling the transcription of imprinted genes through its ability to bind to methylated DNA. The importance of this protein for normal development and physiological function is demonstrated by Rett syndrome which occurs when MECP2 is mutated (Amir et al. 1999).

There are some diseases with multiple causes which only in some cases involve errors to the imprinting mechanism or alterations to imprinted genes. Cancer is one such disease, with some cases of cancer being identified as having a cause linked to genomic imprinting while many other incidences of the disease occur because of unrelated problems. In some instances, human tumour cells have been found to overexpress one or more of Dnmt1s, 3a and 3b, with the largest upregulation occurring to Dnmt3b (Robertson et al. 1999). These results support the previous observations of abnormal methylation levels seen in tumour cells. One cancer which demonstrates such raised Dnmt levels is acute myelogenous leukaemia; it may be that this overexpression of the Dnmt enzymes accounts for the hypermethylation and silencing of an important tumour suppressor gene (Mizuno et al. 2001).

\section{Conclusion}

Genomic imprinting is a gene transcription control mechanism which is vital for normal healthy offspring. Although in recent years there has been a huge volume of work undertaken to elucidate the mechanisms behind genomic imprinting there are still many unanswered questions. Recent data have demonstrated that there are species differences in the imprinting mechanism which still need to be fully explored but could have implications for the success of cloning attempts. Additionally, knowledge of genomic imprinting may aid the understanding of some human diseases and offer potential therapies. The field of ART will also benefit from a greater understanding of genomic imprinting, resulting in improved techniques with an increased success rate and, most importantly, a safer outcome.

\section{Acknowledgements}

Support by MRC and BBSRC is gratefully acknowledged, the authors declare that there is no conflict of interest that would prejudice impartiality of this scientific work

\section{References}

Amir RE, Van den Vegver IB, Wan M, Tran CQ, Francke U \& Zoghbi HY 1999 Rett syndrome is caused by mutations in X-linked MECP2, encoding methyl-CpG-binding protein 2. Nature Genetics 23 185-188.

Beaudet AL \& Jiang YH 2002 A rheostat model for a rapid and reversible form of imprinting-dependent evolution. American Journal of Human Genetics 70 1389-1397.

Beaujean N, Taylor JE, McGarry M, Gardner JO, Wilmut I, Loi P, Ptak G, Galli C, Lazzari G, Bird A, Young LE \& Meehan RR 2004 The effect of interspecific oocytes on demethylation of sperm DNA. PNAS 101 7636-7640.

Beechey CV, Cattanach BM, Blake A, \& Peters J 2005 MRC Mammalian Genetics Unit, Harwell, Oxforshire. World Wide Web site - Mouse imprinting data and references 9 (http: //www.mgu.har.mrc.ac.uk/research/imprinting/).

Benchaib M, Braun V, Ressnikof D, Lornage J, Durand P, Niveleau A \& Guerin IF 2005 Infuence of global sperm DNA methylation on IVF results. Human Reproduction 30 768-773.

Bhattacharya SK, Ramchandani S, Cervoni N \& Szyf M 1999 A mammalian protein with specific demethylase activity for $\mathrm{mCpG}$ DNA. Nature 397 579-583.

Bourc'his D \& Bestor TH 2004 Meiotic catastrophe and retrotransposon reactivation in male germ cells lacking Dnmt3L. Nature 431 96-99.

Bourc'his D, Xu GL, Lin CS, Bollman B \& Bestor TH 2001 Dnmt3L and the establishment of maternal genomic imprints. Science 294 2536-2539.

Carlson LL, Page AW \& Bestor TH 1992 Properties and localization of DNA methyltransferase in preimplantation mouse embryos: implications for genomic imprinting. Genes and Development 6 2536-2541.

Chung YG, Ratnam S, Chaillet JR \& Latham KE 2003 Abnormal regulation of DNA methyltransferase expression in cloned mouse embryos. Biology of Reproduction 69 146-153.

Costello JF \& Plass C 2001 Methylation matters. Journal of Medical Genetics 38 285-303.

Cox GF, Burger J, Lip V, Mau UA, Sperling K, Wu BL \& Horsthemke B 2002 Intracytoplasmic sperm injection may increase the risk of imprinting defects. American Journal of Human Genetics $\mathbf{7 1}$ $162-164$.

Dean W, Santos F, Stojkovic M, Zakhartchenko V, Walter J, Wolf E \& Reik W 2001 Conservation of methylation reprogramming in mammalian development: aberrant reprogramming in cloned embryos. PNAS 98 13734-13738. 
DeBaun MR, Niemitz EL \& Feinberg AP 2003 Association of in vitro fertilization with Beckwith-Wiedemann syndrome and epigenetic alterations of LIT1 and H19. American Journal of Human Genetics 72 156-160.

Doherty AS, Mann MR, Tremblay KD, Bartolomei MS \& Schultz RM 2000 Differential effects of culture on imprinted H19 expression in the preimplantation mouse embryo. Biology of Reproduction 62 $1526-1535$.

Eggenschwiler J, Ludwig T, Fisher P, Leighton PA, Tilghman SM \& Efstratiadis A 1997 Mouse mutant embryos overexpressing IGF-II exhibit phenotypic features of the Beckwith-Wiedemann and Simpson-Golabi-Behmel syndromes. Genes and Development 11 3128-3142.

Ehrlich M 2003 The ICF syndrome, a DNA methyltransferase 3B deficiency and immunodeficiency disease. Clinical Immunology 109 $17-28$.

Feng Q \& Zhang Y 2001 The MeCP1 complex represses transcription through preferential binding, remodeling, and deacetylating methylated nucleosomes. Genes and Development 15 $827-832$

Fujita N, Takebayashi S, Okumura K, Kudo S, Chiba T, Saya H \& Nakao M 1999 Methylation-mediated transcriptional silencing in euchromatin by methyl-CpG binding protein MBD1 isoforms. Molecular and Cellular Biology 19 6415-6426.

Fujita N, Watanabe S, Ichimura T, Tsuruzoe S, Shinkai Y, Tachibana M, Chiba T \& Nakao M 2003 Methyl-CpG binding domain 1 (MBD1) interacts with the Suv39h1-HP1 heterochromatic complex for DNA methylation-based transcriptional repression. Journal of Biological Chemistry 278 24132-24138.

Gicquel C, Gaston V, Mandelbaum J, Siffroi JP, Flahault A \& Le Bouc Y 2003 In vitro fertilization may increase the risk of BeckwithWiedemann syndrome related to the abnormal imprinting of the KCN1OT gene. American Journal of Human Genetics 72 $1338-1341$.

Golding MC \& Westhusin ME 2003 Analysis of DNA (cytosine 5) methyltransferase mRNA sequence and expression in bovine preimplantation embryos, fetal and adult tissues. Gene Expression Patterns 3 551-558.

Guy J, Hendrich B, Holmes M, Martin JE \& Bird A 2001 A mouse Mecp2-null mutation causes neurological symptoms that mimic Rett syndrome. Nature Genetics 27 322-326.

Hajkova P, Erhardt S, Lane N, Haaf T, El Maarri O, Reik W, Walter J \& Surani MA 2002 Epigenetic reprogramming in mouse primordial germ cells. Mechanisms of Development 117 15-23.

Hata K, Okano M, Lei H \& Li E 2002 Dnmt3L cooperates with the Dnmt3 family of de novo DNA methyltransferases to establish maternal imprints in mice. Development 129 1983-1993.

Hendrich B \& Bird A 1998 Identification and characterization of a family of mammalian methyl-CpG binding proteins. Molecular and Cellular Biology 18 6538-6547.

Hendrich B, Hardeland U, Ng HH, Jiricny J \& Bird A 1999 The thymine glycosylase MBD4 can bind to the product of deamination at methylated CpG sites. Nature 401 301-304.

Hendrich B, Guy J, Ramsahoye B, Wilson VA \& Bird A 2001 Closely related proteins MBD2 and MBD3 play distinctive but interacting roles in mouse development. Genes and Development 15 710-723.

Hermann A, Schmitt S \& Jeltsch A 2003 The human Dnmt2 has residual DNA-(cytosine-C5) methyltransferase activity. Journal of Biological Chemistry 278 31717-31721.

Howell CY, Bestor TH, Ding F, Latham KE, Mertineit C, Trasler JM \& Chaillet JR 2001 Genomic imprinting disrupted by a maternal effect mutation in the Dnmt1 gene. Cell 104 829-838.

Iguchi-Ariga SM \& Schaffner W 1989 CpG methylation of the cAMPresponsive enhancer/promoter sequence TGACGTCA abolishes specific factor binding as well as transcriptional activation. Genes and Development 3 612-619.

Jones PL, Veenstra GJ, Wade PA, Vermaak D, Kass SU, Landsberger N, Strouboulis J \& Wolffe AP 1998 Methylated DNA and MeCP2 recruit histone deacetylase to repress transcription. Nature Genetics 19 187-191.

Jue K, Bestor TH \& Trasler JM 1995 Regulated synthesis and localization of DNA methyltransferase during spermatogenesis. Biology of Reproduction 53 561-569.

Kaneda M, Okano M, Hata K, Sado T, Tsujimoto N, Li E \& Sasaki H 2004 Essential role for de novo DNA methyltransferase Dnmt3a in paternal and maternal imprinting. Nature 429 900-903.

Kerjean A, Dupont JM, Vasseur C, Le Tessier D, Cuisset L, Paldi A, Jouannet P \& Jeanpierre M 2000 Establishment of the paternal methylation imprint of the human $\mathrm{H} 19$ and MEST/PEG1 genes during spermatogenesis. Human Molecular Genetics 9 2183-2187.

Ko YG, Nishino K, Hattori N, Arai Y, Tanaka S \& Shiota K 2005 Stage-by-stage change in DNA methylation status of DNA methyltransferase 1 (Dnmt1) locus during mouse early development. Journal of Biological Chemistry 280 9627-9634.

Kono T, Obata Y, Yoshimzu T, Nakahara T \& Carroll J 1996 Epigenetic modifications during oocyte growth correlates with extended parthenogenetic development in the mouse. Nature Genetics 13 91-94.

Kono T, Obata Y, Wu Q, Niwa K, Ono Y, Yamamoto Y, Park ES, Seo JS \& Ogawa H 2004 Birth of parthenogenetic mice that can develop to adulthood. Nature 428 860-864.

La Salle S, Mertineit C, Taketo T, Moens PB, Bestor TH \& Trasler JM 2004 Windows for sex-specific methylation marked by DNA methyltransferase expression profiles in mouse germ cells. Developmental Biology 268 403-415.

Li E 2002 Chromatin modification and epigenetic reprogramming in mammalian development. Nature Reviews in Genetics $\mathbf{3}$ $662-673$.

Liu K, Wang YF, Cantemir C \& Muller MT 2003 Endogenous assays of DNA methyltransferases: evidence for differential activities of DNMT1, DNMT2, and DNMT3 in mammalian cells in vivo. Molecular and Cellular Biology 23 2709-2719.

Lucifero D, Mann MR, Bartolomei MS \& Trasler JM 2004 Genespecific timing and epigenetic memory in oocyte imprinting. Human Molecular Genetics 13 839-849.

McLaren RJ \& Montgomery GW 1999 Genomic imprinting of the insulin-like growth factor 2 gene in sheep. Mammalian Genome 10 588-591.

Maher ER, Brueton LA, Bowdin SC, Luharia A, Cooper W, Cole TR, Macdonald F, Sampson JR, Barratt CL, Reik W \& Hawkins MM 2003 Beckwith-Wiedemann syndrome and assisted reproduction technology (ART). Journal of Medical Genetics 40 62-64.

Marques CJ, Carvalho F, Sousa M \& Barros A 2004 Genomic imprinting in disruptive spermatogenesis. Lancet 363 1700-1702.

Mertineit C, Yoder JA, Taketo T, Laird DW, Trasler JM \& Bestor TH 1998 Sex-specific exons control DNA methyltransferase in mammalian germ cells. Development 125 889-897.

Mizuno S, Chijiwa T, Okamura T, Akashi K, Fukumaki Y, Niho Y \& Sasaki H 2001 Expression of DNA methyltransferases DNMT1, 3A, and $3 \mathrm{~B}$ in normal hematopoiesis and in acute and chronic myelogenous leukemia. Blood 97 1172-1179.

Moncla A, Malzac P, Livet MO, Voelckel MA, Mancini J, Delaroziere JC, Philip N \& Mattei JF 1999 Angelman syndrome resulting from UBE3A mutations in 14 patients from eight families: clinical manifestations and genetic counselling. Journal of Medical Genetics 36 $554-560$

Moore T \& Haig D 1991 Genomic imprinting in mammalian development: a parental tug-of-war. Trends in Genetics 7 45-49.

Nan X, Campoy FJ \& Bird A 1997 MeCP2 is a transcriptional repressor with abundant binding sites in genomic chromatin. Cell $\mathbf{8 8}$ $471-481$.

Nan X, Ng HH, Johnson CA, Laherty CD, Turner BM, Eisenman RN \& Bird A 1998 Transcriptional repression by the methyl-CpG-binding protein MeCP2 involves a histone deacetylase complex. Nature 393 386-389.

$\mathrm{Ng} \mathrm{HH}$, Zhang Y, Hendrich B, Johnson CA, Turner BM, ErdjumentBromage H, Tempst P, Reinberg D \& Bird A 1999 MBD2 is a 
transcriptional repressor belonging to the MeCP1 histone deacetylase complex. Nature Genetics 23 58-61.

Ng HH, Jeppesen P \& Bird A 2000 Active repression of methylated genes by the chromosomal protein MBD1. Molecular and Cellular Biology 20 1394-1406.

Obata Y \& Kono T 2002 Maternal primary imprinting is established at a specific time for each gene throughout oocyte growth. Journal of Biological Chemistry 277 5285-5289.

Orstavik KH, Eiklid K, van der Hagen CB, Spetalen S, Kierulf K, Skjeldal O \& Buiting K 2003 Another case of imprinting defect in a girl with Angelman syndrome who was conceived by intracytoplasmic semen injection. American Journal of Human Genetics 72 218-219.

Oswald J, Engemann S, Lane N, Mayer W, Olek A, Fundele R, Dean W, Reik W \& Walter J 2000 Active demethylation of the paternal genome in the mouse zygote. Current Biology 10 475-478.

Prokhortchouk A, Hendrich B, Jorgensen $H$, Ruzov A, Wilm $M$, Georgiev G, Bird A \& Prokhortchouk E 2001 The p120 catenin partner Kaiso is a DNA methylation-dependent transcriptional repressor. Genes and Development 15 1613-1618.

Reik W \& Dean W 2001 DNA methylation and mammalian epigenetics. Electrophoresis 22 2838-2843.

Robertson KD, Uzvolgyi E, Liang G, Talmadge C, Sumegi J, Gonzales FA \& Jones PA 1999 The human DNA methyltransferases (DNMTs) 1, 3a and 3b: coordinate mRNA expression in normal tissues and overexpression in tumors. Nucleic Acids Research 27 2291-2298.

Ruzov A, Dunican DS, Prokhortchouk A, Pennings S, Stancheva I, Prokhortchouk E \& Meehan RR 2004 Kaiso is a genome-wide repressor of transcription that is essential for amphibian development. Development 131 6185-6194.

Santos F, Hendrich B, Reik W \& Dean W 2002 Dynamic reprogramming of DNA methylation in the early mouse embroy. Develop mental Biology 241 172-182.

Spears N, Boland NI, Murray AA \& Gosden RG 1994 Mouse oocytes derived from in vitro grown primary ovarian follicles are fertile. Human Reproduction 9 527-532.

Surani MA 1998 Imprinting and the initiation of gene silencing in the germ line. Cell 93 309-312.

Tamashiro KL, Wakayama T, Akutsu H, Yamazaki Y, Lachey JL, Wortman MD, Seeley RJ, D'Alessio DA, Woods SC, Yanagimachi R \& Sakai RR 2002 Cloned mice have an obese phenotype not transmitted to their offspring. Nature Medicine 8 262-267.
Tang LY, Reddy MN, Rasheva V, Lee TL, Lin MJ, Hung MS \& Shen CK 2003 The eukaryotic DNMT2 genes encode a new class of cytosine-5 DNA methyltransferases. Journal of Biological Chemistry $27833613-33616$

Taunton J, Hassig CA \& Schreiber SL 1996 A mammalian histone deacetylase related to the yeast transcriptional regulator Rpd3p. Science 272 408-411.

Tycko B \& Morison IM 2002 Physiological functions of imprinted genes. Journal of Cellular Physiology 192 245-258.

Ueda T, Abe K, Miura A, Yuzuriha M, Zubair M, Noguchi M, Niwa $K$, Kawase $Y$, Kono $T$, Matsuda $Y$, Fujimoto $H$, Shibata $H$, Hayashizaki Y \& Sasaki H 2000 The paternal methylation imprint of the mouse $\mathrm{H} 19$ locus is acquired in the gonocyte stage during foetal testis development. Genes to Cells 5 649-659.

Varmuza S \& Mann M 1994 Genomic imprinting - defusing the ovarian time bomb. Trends in Genetics 10 118-123.

Wade PA 2001 Methyl CpG-binding proteins and transcriptional repression. BioEssays 23 1131-1137.

Walsh CP, Chaillet JR \& Bestor TH 1998 Transcription of IAP endogenous retroviruses is constrained by cytosine methylation. Nature Genetics 20 116-117.

Young LE, Sinclair KD \& Wilmut I 1998 Large offspring syndrome in cattle and sheep. Reviews of Reproduction 3 155-163.

Young LE, Fernandes K, McEvoy TG, Butterwith SC, Gutierrez CG, Carolan C, Broadbent PJ, Robinson JJ, Wilmut I \& Sinclair KD 2001 Epigenetic change in IGF2R is associated with fetal overgrowth after sheep embryo culture. Nature Genetics 27 153-154.

Yu F, Thiesen J \& Stratling WH 2000 Histone deacetylase-independent transcriptional repression by methyl-CpG-binding protein 2 . Nucleic Acids Research 28 2201-2206.

Zhao X, Ueba T, Christie BR, Barkho B, McConnell MJ, Nakashima K, Lein ES, Eadie BD, Willhoite AR, Muotri AR, Summers RG, Chun J, Lee KF \& Gage FH 2003 Mice lacking methyl-CpG binding protein 1 have deficits in adult neurogenesis and hippocampal function. PNAS 100 6777-6782.

Received 26 July 2004

First decision 17 September 2004

Revised manuscript received 26 Jan 2005

Accepted 26 May 2005 